\title{
'ALĀQAH DILĀLIYYAH BAYNA ALFĀDZ SAKĪNAH WA MAWADDAD WA RAHMAH Fİ AL QURĀN AL KARĪM
}

\section{علاقة دلالية بين ألفاظ سكينة ومودة ورحمة في القرآن الكريم Jamilatussa`diyah}

UIN Sunan Gunung Djati Bandung, jamilatussadiyah98@gmail.com

\section{ملخص البحث}

إن القرآن الكريم معجزة الإسلام الخالدة ومن مظاهر إعجاز القرآن الكريم يبدو من جهة لغته البديعة

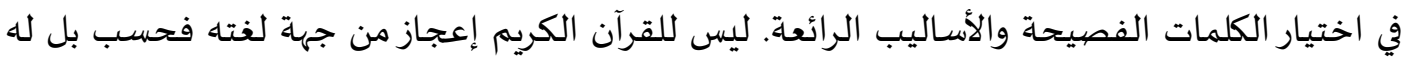

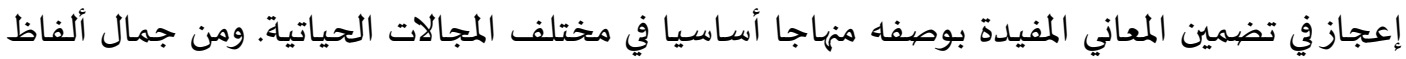

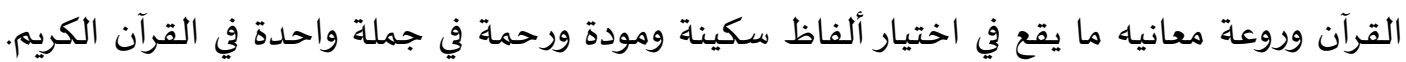
وإن لهذه الألفاظ الثلاثة معانيا مقصودة مختلفة وعلاقة دلالية بينها. واستعمل القرآن الكريم ألفاظ

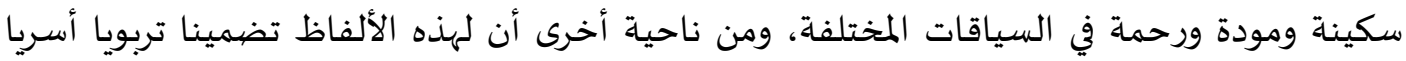

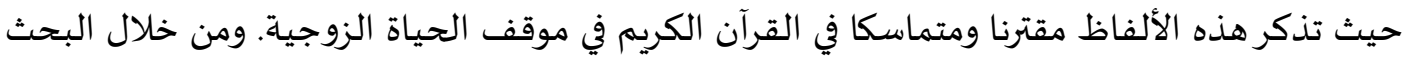

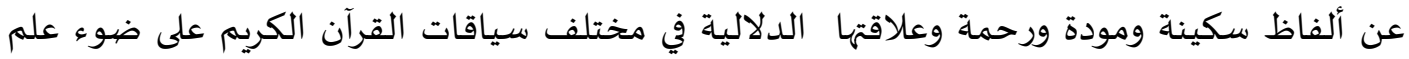
الدلالة ومحور التربية تنكشف المعاني المعاني المعجمية والسياقية لكل منها والعلاقة الدلالية بينها كما ولها تنكشف وجوه التضمين التربوي الأسري منها. الكلمات المفتاحية: دلالة، سكينة ومودة ورحمة، التضمين التربوي التربئ الأسري.

\section{Abstrak}

Al Quran adalah mukjizat Islam yang kekal. Salah satu bentuk kemukjizatan Al Quran adalah dari aspek bahasanya dalam pemilihan kata yang tepat dan gaya bahasa yang indah. Aspek kemukjizatan Al Quran pun nampak dalam kandungannya yang berguna bagi manusia karena merupakan pedoman hidup yang utama dalam berbagai aspek kehidupan. Diantara bentuk keindahan kata dan makna Al Quran terletak pada pemilihan kata sakinah, mawaddah, dan rahmah dalam satu kalimat. Ketiga kata tersebut memiliki makna tertentu yang 
Ta'lim al-'Arabiyyah : Jurnal Pendidikan Bahasa Arab dan Kebahasaaraban, 3 (2), 2019

berbeda-beda akan tetapi saling berhubungan satu sama lain. Al Quran menggunakan kata sakinah, mawaddah, dan rahmah dalam beragam konteks. Disamping itu ketiga kata tersebut berimplikasi terhadap pendidikan keluarga sesuai dengan penyebutannya secara berurutan dalam satu kalimat tentang tema kehidupan rumah tangga. Melalui penelitian tentang relasi makna kata sakinah, mawaddah, dan rahmah perspektif semantik dan bingkai pendidikan, maka akan tersingkap makna masing-masing, baik secara leksikal maupun kontekstual; dan relasi makna antara ketiganya, selanjutnya akan tersingkap pula aspek-aspek pendidikan keluarga dari ketiga kata tersebut.

Kata Kunci: Semantik, Sakinah, Mawaddah, Rahmah, Pendidikan Keluarga

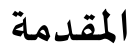

مما لاريب فيه أن القرآن الكريم هو الكتاب الذي يعظّمها المسلمون بوصفه منهاجا

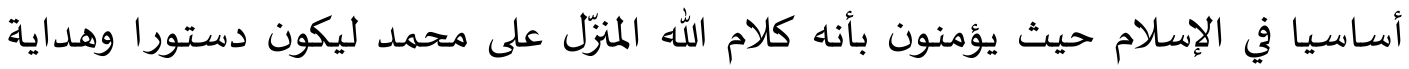

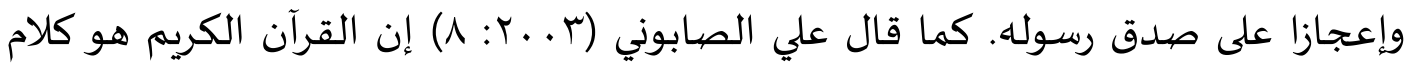

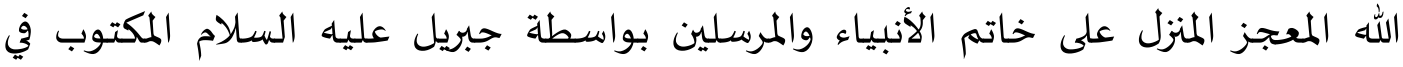

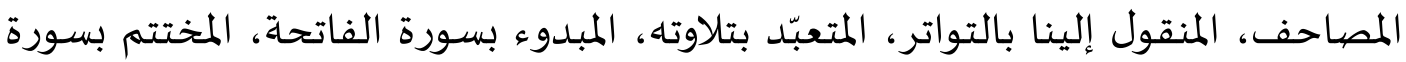
الناس.

والإعجاز الذي يتحمله القرآن يشمل عدّة النواحي من ناحية اللغة والأمور الغيبية

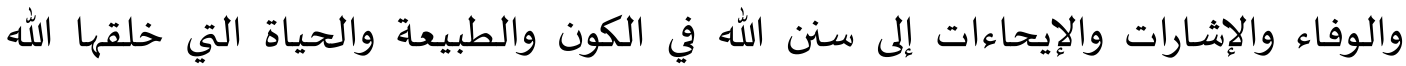

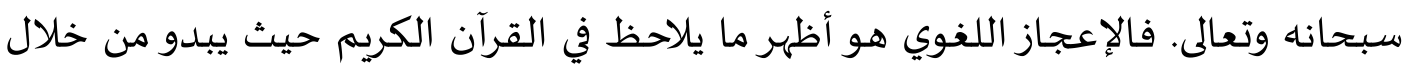
اللغة التي يستخدمها في صنوف الكلام وبراعة ألفاظه. ومن مظاهر إعجاز القرآن الكريم اختيار الكلمات أو الألفاظ للدلالة على معانيها

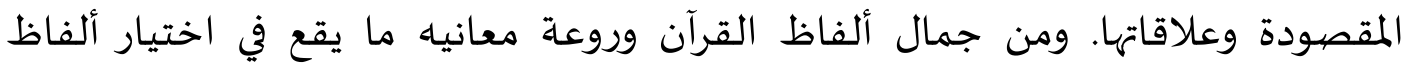
سكينة ومودّة و رحمة في جملة واحدة في القرآن الكريم. كما قال الله تبارك وتعالى

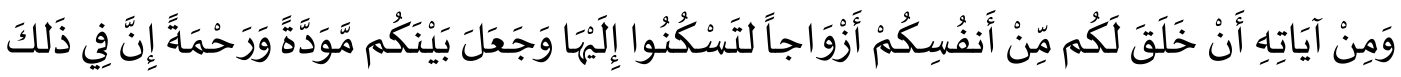

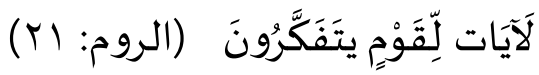
و يفترض أن لتلك الألفاظ معانيا مقصودة مختلفة وإن كانت متحدة في حقيقتها، بل لكل هذه الألفاظ خصية المعاني. كثيرا ما يفهم في الواقع أن استخدام ألفاظ سكينة ومودّة ورحمة لكل منها معنى جزئي، لكناه بعد إمعان التأمل والنظر إليه توجد العلاقات الدلالية الوطيدة بينها. وهذا 
Ta'Cim al-'Arabiyyah : Jumal Pendidikan Bahasa Arab dan Kebahasaaraban, 3 (2), 2019

مما يؤيد إعجاز القرآن الكريم من ناحية روعة ألفاظه وثروة معانيه. وهذه الألفاظ الثلاثة منها ما يستعمل في آيات مستقلة وهي الأكثر وما يستعمل في آية واحدة وهي في الآية (Y)

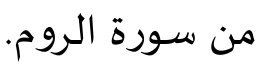
ليس للقرآن الكريم إعجاز من جهة لغتاه فحسب بل لله إعجاز في تضمين المعاني

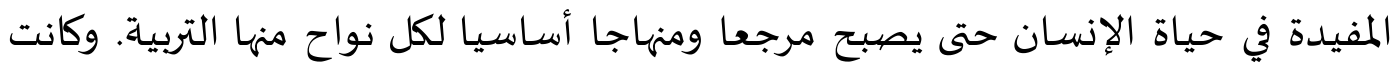
التربية لها دور هام في تقدم الشعوب ورقيها لأنها تزيد من نوعية الفرد وترفع قيمتاه ومقدار الإنا ما يحصل منها وضرورية لكل فرد من أفراد المجتمع، وبخاصة لهدم التربية الأسرية.

طريقة البحث

طريقة البحث هي الأدوات اللازمة للبحث عن البيانات والمعلومات (فاطمة جاجاسودرما، بr|199: rr). وأما طريقة البحث المستخدمة فهي طريقة تحليل المضهمون

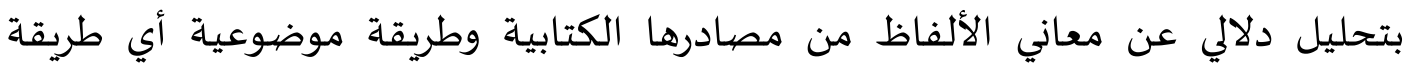
تستخدم في تفسير آيات القرآن الكريم التي تتعلق بموضع خاص بـمنمع كل آية تتصل باء. ا ا. تحديد البيانات

البيانات في الواقعية أو المعلومات أو البراهين مع أنها مصدر أو آلة للاستنباط أو التقرير. مصادر البيانات من ناحياة النوع تنقسم إلى قسمين: المصادر الأساسية والمصادر الإضافية. فالمصادر الأسـاسية هي مصدر البيانات الأولى والتي تتدخل في المصادر الأسـاسية في هذا البحث هي الكتب المعتلقة بالمشكلة المبحوثة مثل: القرآن الكريم والتفاسير والمعاجيم. وأما المصادر الإضافية هي الكتب التي تتعلق بالموضوع من الكتب العربية والأجنبية. وكلاهما من هذين النوعين مهم جدا في عملية البحث. r أسلوب جمع البيانات

وفي هذه الخطوة جمعت الكاتبة آيات قرآنية واستخدم فيها ألفاظ سكينة ومودة

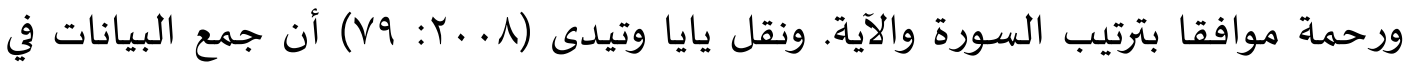

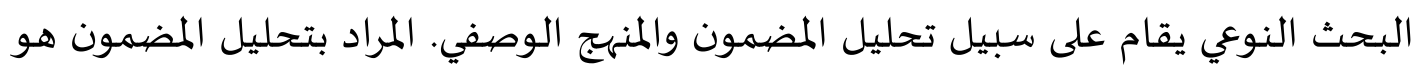

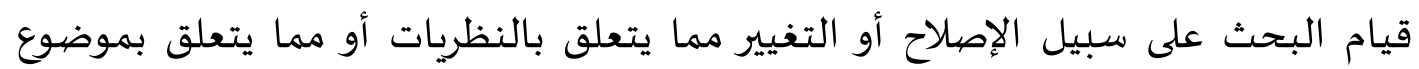


Ta'lim al-'Arabiyyah : Jurnal Pendidikan Bahasa Arab dan Kebahasaaraban, 3 (2), 2019

البحث. أما المراد بالمنهج الوصفي هو البحث العلمي على سبيل التفكير أوشرح المصادر أو

$$
\text { النظريات المعيّنة. }
$$

وتحليل البيانات المستعملة في هذه الدراسة بالخطوات الآتية:

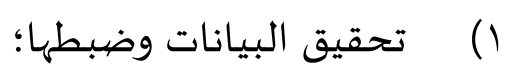

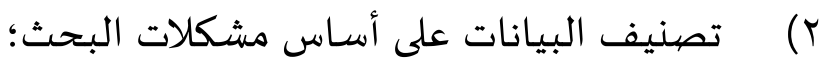

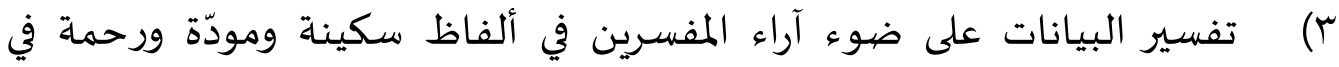

$$
\text { تقديم نتائج البحث. الكريم حسب سياقاتها؛ }
$$

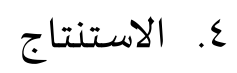

إن الاستنتاج هو الحصول على النتائج من عملية مخصيوصة. وأهمية الاستنتاج

لتحصيل ما يهدف إليه موضوع البحث من خلال تحليل البيانات الموجودة. وما يهدف إليه هذا البحث هو الوصول إلى الإجابة عن الأسئلة المقررة وهي معرفة المعاني المعجمية والسياقية من الألفاظ سكينة ومودّة ورحمة في القرآن الكريم وعلاقتها الدلالية وتضيمينها

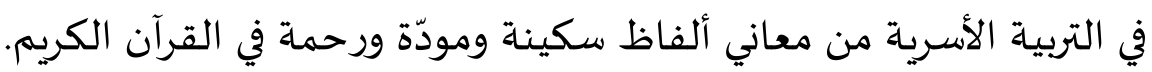

البحث

علم الدلالة وما يتعلق به ا ا. مفهوم علم الدلالة وأهميته

إن علم الدلالة من مستويات الدرس اللغوي الذي يقوم بدراسة المعنى والمقاصيد.

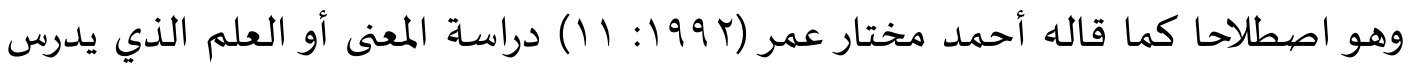

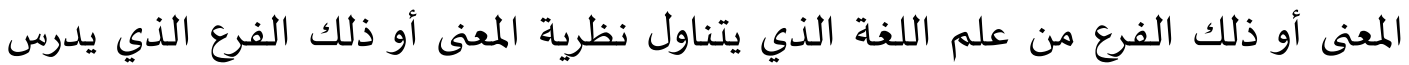
الشروط الواجب توافرها في الرموز حتى يكون قادرا على حمل المعنى. ويعدّ هذا العلم من

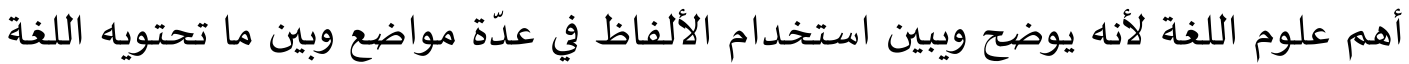
من كلمات قادرة على التعبير عن أي فكرة وشعور ووصفها وصفا دقيقا. 
Ta'Cim al-'Arabiyyah : Jumal Pendidikan Bahasa Arab dan Kebahasaaraban, 3 (2), 2019

فضرورية علم الدلالة تظهر حينما تفهم طبيعة اللغة من خلال فهم المعنى لأن المعنى يلعب دورا أساسيا في كل مستويات التحليل اللغوي بدءا من التحليل الفونيمي، بل يلعب دورا كبيرا في تطبيقات كثيرة لعلم اللغة مثل طرق الاتصال وتعليم اللغة والترجمة ودراسة اكتساب اللغة، وبدون المعنى لا يمكن أن يكون هناك اللغة. قسّمت الدلالة في علم اللغة إلى أنواع مختلفة على حسب المدخلات المدات التي تتدخل في

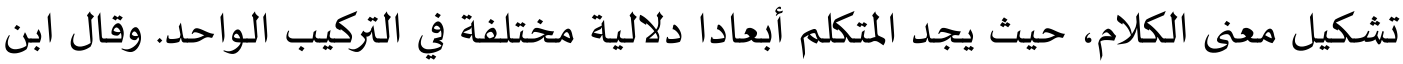

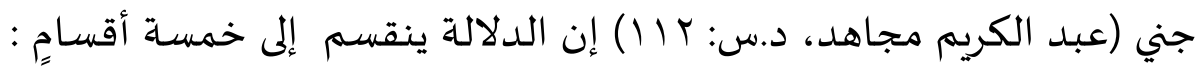

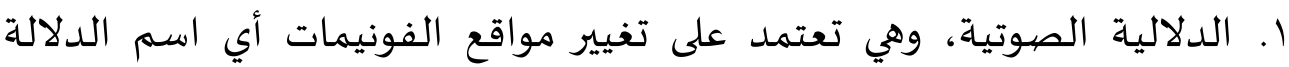

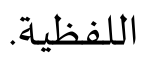

r. الدلالة الصرفية، تقوم هذه الدلالة على ما تؤديه الأوزان الصرفية العربية وأبنيتها من معان. r. الدلالة المعجمية، تحصل من خلال الكشف عمان في المعجم وما يقع في سياق الحال في استعمال كلمة أو عبارة.

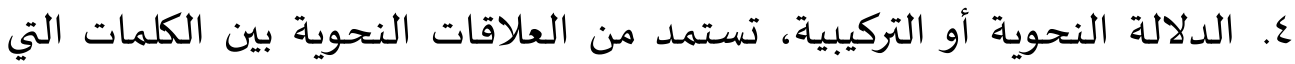
تتخذ كل منها موقعا معينا في الجملة. 0. الدلالة الاجتماعياة، لا يمكن فهمها إلا من خلال السياق لا بد من تداخل عناصر أخرى غير لغوية تساهم في توضيح المعنى المقصود من خلال شخصية المهنية

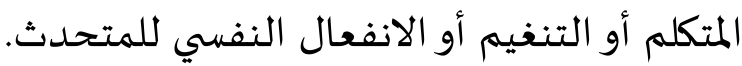

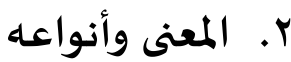

أما المعنى عند بلومفيد (Bloomfiled) فهو المقام الذي يقول فيه المتكلم كلمة أو جملة أو استجابة عن المستمع. إذا المعنى عند بلومفيد هو المقام والاستجابة عند المتكلم. وفي المعجم الإندونيسي الكبير إن المعنى هو عبارة عن كل كلمة أو غرض المهابه المكلام والكتابة أوشيئ

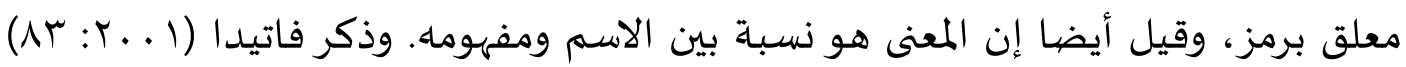
في كتاباه Semantik Leksikal عدة مفاهيم المعنى وهي: 1. علاقة وثيقة بين الأشياء الفريدة غير المبحوثة؛ 
Ta'Cim al-'Arabiyyah : Jurnal Pendidikan Bahasa Arab dan Kebahasaaraban, 3 (2), 2019

$$
\begin{aligned}
& \text { r. . عبارة عن كلمة واقعة في القاموس؛ }
\end{aligned}
$$

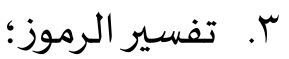

$$
\begin{aligned}
& \text { ع. استخدام الرمز الذي يحمل إلى المقصود؛ } \\
& \text { 0. نسبة شيئ واقعي مع رمزه الصوتي. }
\end{aligned}
$$

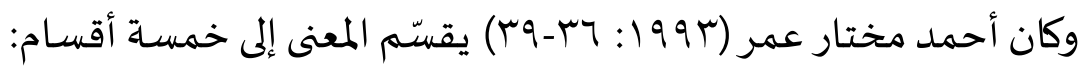

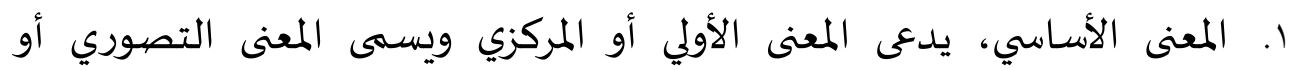

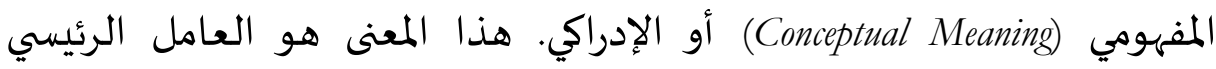
للاتصال اللغوي والممثل الحقيقي للوظيفة الأسـاسية للغة. r. المعنى الإضافي أو العرضي أو الثانوي أو التضيميني (Additional Meaning). وهو

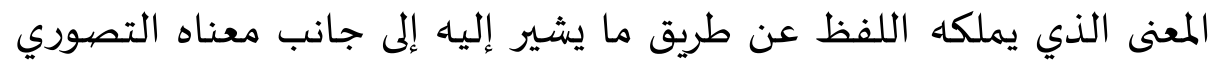
الخالص. - المبك. r. المعنى الأسلوبي (Stylistic Meaning) أو الاجتماعي وهو ذلك النوع من المعنى الذي تحمله قطعة من اللغة بالنسبة للظروف الاجتماعية لمستعملها والمنطقة الجغرافية التي ينتمي إليها. ع. المعنى النفسي (Subjective Meaning) وهو يشير إلى ما يتضمناه اللفظ من دلالات

$$
\text { عند الفرد .فهو بذلك معنى فردي ذاتي. }
$$

0. المعنى الإيحائي (Collocative Meaning) وهو ذلك النوع بـ من المعنى الذي يتعلق

$$
\text { بكلمات ذات مقدرة خاصية على الإيحاء. }
$$

معاني ألفاظ سكينة ومودة ورحمة معجميا وسياقيا

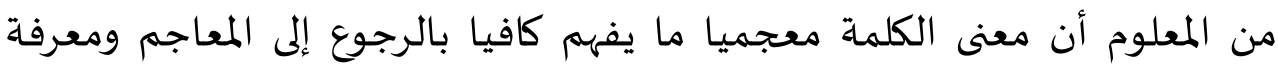

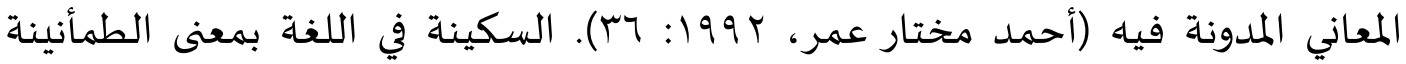
والاستقرار وهو يدل على خلاف الطيش والاضطراب (ابن فارس في كتابه مقاييس اللغة (19V9: 11 ). والسكينة هي الطمأنينة والوقار والسكون الذي ينزله الله في قلب عبده عند اضطرابه من شدة المخاوف (ابن القيم، سب 17: r.0). والمودة هي محبة الشيئ وتمني

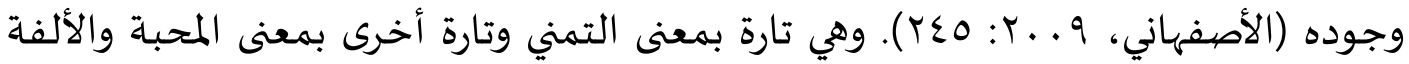


Ta'Cim al-'Arabiyyah : Jumal Pendidikan Bahasa Arab dan Kebahasaaraban, 3 (2), 2019

الخالصة. وإنها شعور بالانسجام بين الشخصين أو أكثر ينبع من الاحتكاك الاجتماعي

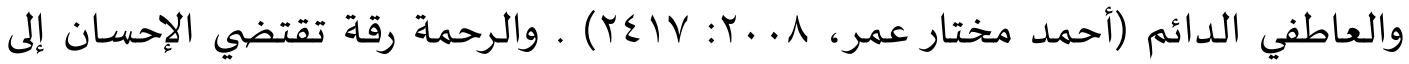

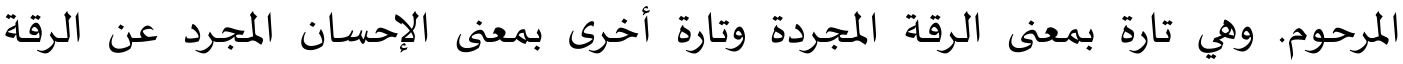

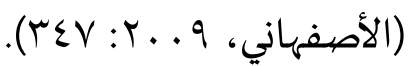

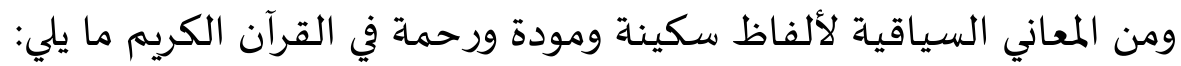

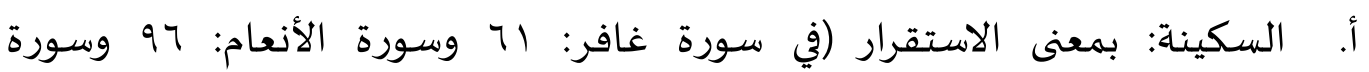

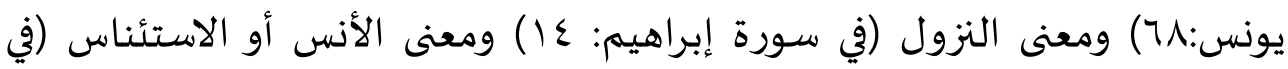

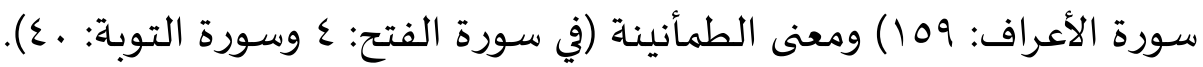

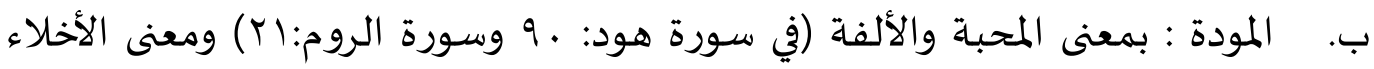

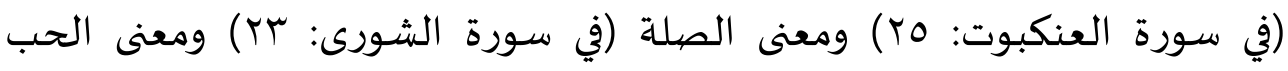
والثناء الحسن (في سورة مريم: 77 (9).

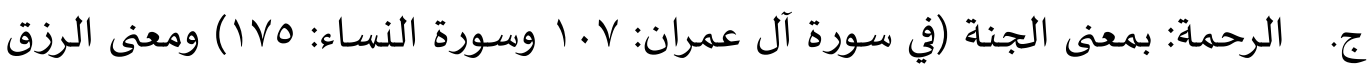

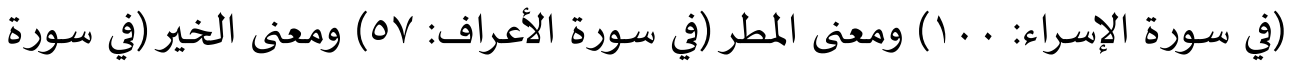

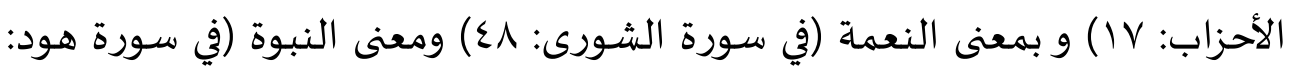

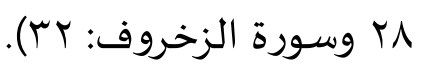

\section{r. - العلاقات الدلالية بين الألفاظ}

إن العلاقات الدلالية مجموعة من العلاقات التي تجمع أطراف النص وتربط بين

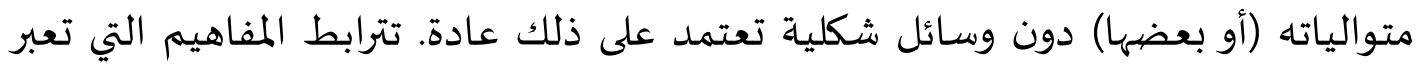

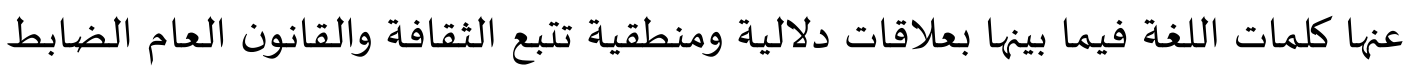
لحركة المجتمع. ينقسم العلاقات الدلالية إلى أربعة أقسام : ا. الترادف، هو دلالة عدد من الكلمات المختلفة على معنى واحد، مثل: عام - سنة حول. r. التضاد، هو وجود كلمتين متشابهتين في معظم المكونات الدلالية ما عدا واحدة أو

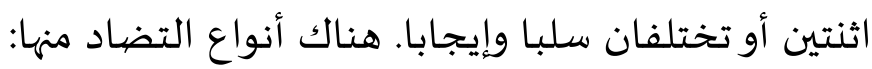


Ta'lim al-'Arabiyyah : Jurnal Pendidikan Bahasa Arab dan Kebahasaaraban, 3 (2), 2019

أ. تضاد حاد، هو أن يقسم مجال المعنى كلمتين ليس بينهما درجات. مثل:

$$
\text { ميت -حي، أعزب - متزوج. }
$$

ب. تضاد متدرج، هو التضياد الذي يكون بين طرفيه درجات. مثل: بارد - حار

$$
\text { (بارد، فاتر، دافئ، ساخن، حار). }
$$

ج. تضاد عكسي، هو التضاد الذي يكون بين كلمتين دلالة على معنين مانين

$$
\text { متلازمين مثل باع - اشترى، زوج - زوجية، }
$$

د. تضاد اتجاهي، هو ما إذا كانت الكلمات المتضيادة من مفردات زوتهات الاتجاهات

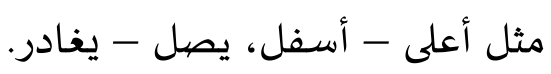

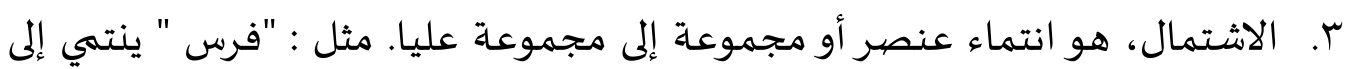

$$
\text { فصيلة أعلى " حيوان ". }
$$

ع. التنافر، هو إذا كانت الكلمات من نفس الحقل وكل واحدة لاتضياد الأخرى ولا

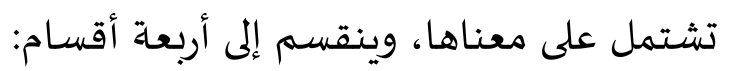

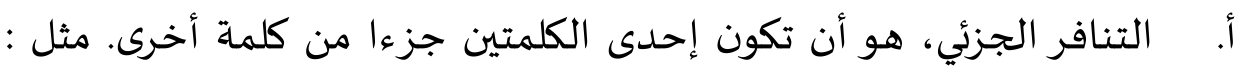

$$
\text { غلاف - كتاب، غصن - شجرة. }
$$

ب. التنافر الدائري، هو الذي يكون بين كلمتين دلالة على فترات متعاقبة

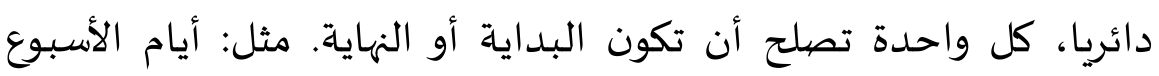

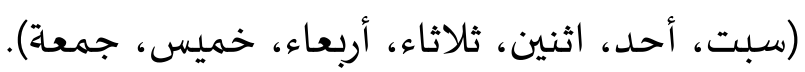

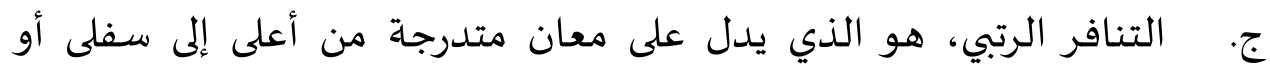
العكس، مثل: مراحل العمر (جنين، طفل، شـاب، رجل، كهل، شيخ).

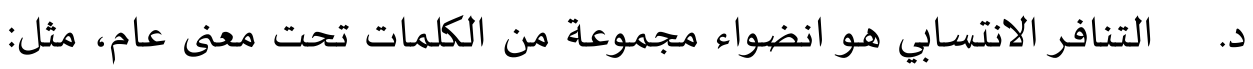
تفاح، برتقال، موز (فواكه)؛ بقرة، غنيماة، حصان (حيوان مئوعن أليف).

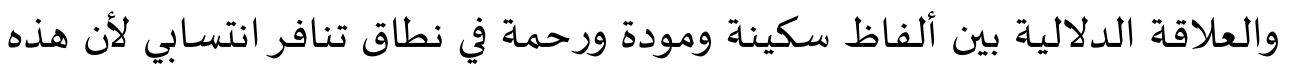
الألفاظ الثلاثة تدل على انضواء مجموعة من الكلمات تحت معنى عام. والمعنى العام من لهن

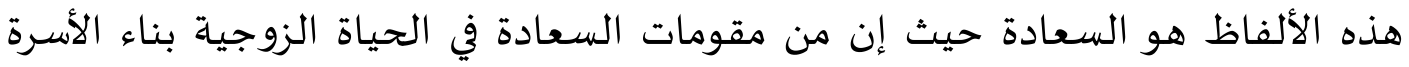

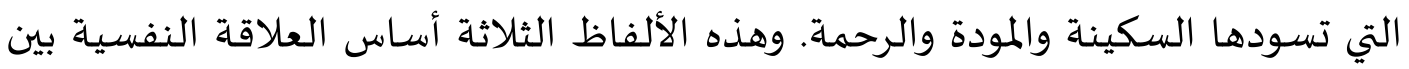


Ta'Cim al-'Arabiyyah : Jumal Pendidikan Bahasa Arab dan Kebahasaaraban, 3 (2), 2019

الرجل والمرأة. والزوجة مثل السكن وبغياب المودة والرحمة ينهار هذا السكن. السكن هو سكينة النفس وطمأنينتها واستقرارها ويقوم هذا السكن على أسـاس المودة والرحمة.

\section{التربية الأسربة}

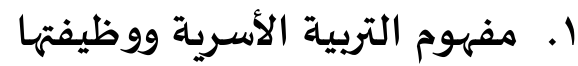

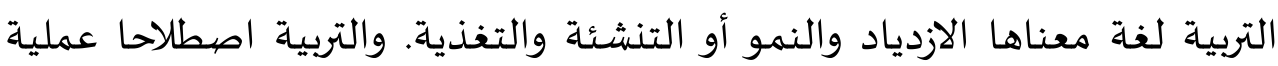
تشكيل الشخصية السوية المتكاملة في جميع جوانها روحيا وعقليا ووجدانيا وخلقيا

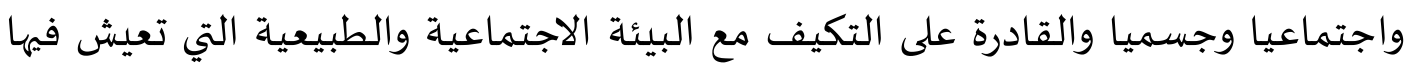

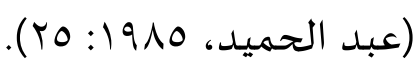

تعرف الأسرة بأنها الخلية الأولى أو الجزء الأساسي في بنية المجتمع. وتتألف في

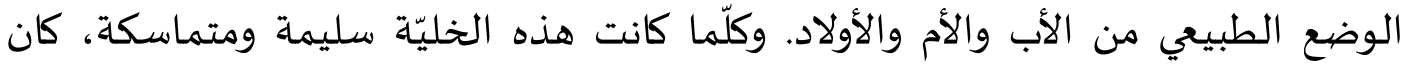
المجتمع بالتالي سليماً ومتماسكاً وقوياً.

تعدّ الوظيفة التربوية من أهمّ الوظائف التي تتولاها الأسرة تجاه أبنائها من خلال تربيتهم ورعايتهم وتلقينهم اللغة والقيم والعادات التي تتماشى والمجتمع بخاصة في المرحلة العمرية الأولى لأن طفولة الكائن البشري أطول طفولة وتهيه بالنسبة للكائنات الحية، ومن ثم نجد الطفل ملتصقا بأسرته لسنوات طويلة. تقع مسؤولية تربية الأبناء على الأباء في المرتبة الأولى والتربية في معناها الشـامل لا لاكياء

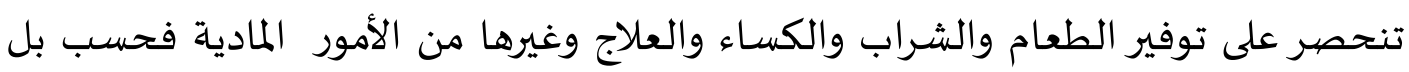

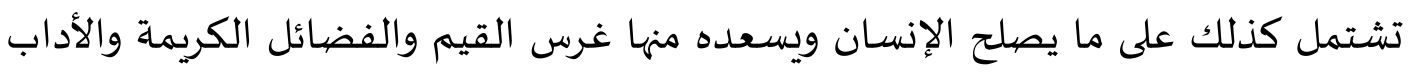

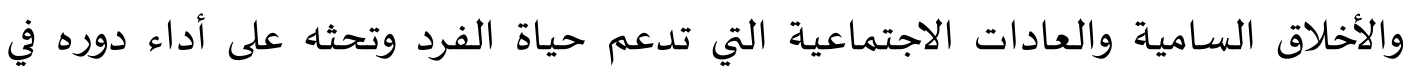

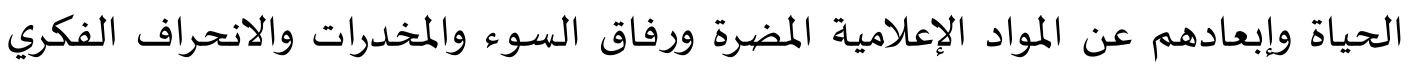
وغيرها من الأعمال السيئة.

\section{r. أسس التربية الأسرية}

تحتوي التربية الأسرية على الأسس التي وضعها الله في الآمور الآتية (عبد الحميد

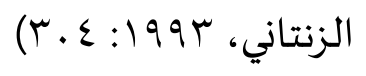


Ta'Cim al-'Arabiyyah : Jurnal Pendidikan Bahasa Arab dan Kebahasaaraban, 3 (2), 2019

أ. التربية الجيسمية، إن جوانب الشخصية الإنسانية متكاملة ويؤثر بعضها

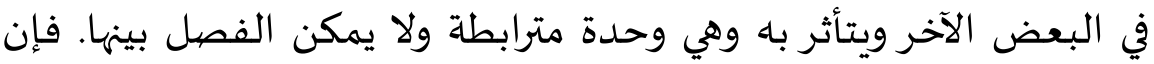
هناك اتصالا وثيقا وتفاعلا مشتركا بين النفس والجسم، النفس تؤثر في الجسم والجسم تؤثر في النفس ولا انفصال بين هذا وذاك (محمدقطب،

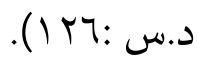
ب. التربية الروحية، هي ترسيخ القوى الروحية وغرس الإيمان في نفوس الأبناء

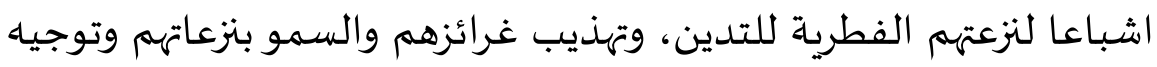
سلوكهم على أساس القيم الروحية والمبادئ والمثل الأخلاقية التي تستمد ولهدئ من الإيمان الصحيح بالله عزّوجلّ. ج. التربية العقلية، هي مساعدة الناشئ على التمكّن من المفاتيح الأولى للعلم والمعرفة والكشف عن الاستعدادات والقدرات العقلية وتنمية الاتجاهات العقلية البناءة الإيجابية وتفجير طاقات الإبداع والخلق والابتكار والاختراع بحسن توجيههم وإرشاداتهم بالأساليب التربوية السليمة.

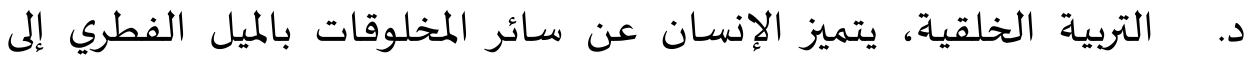

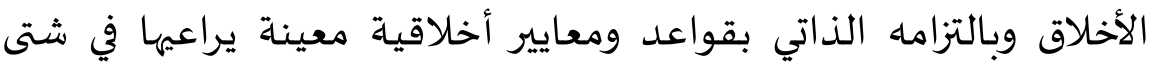
المواقف والاتجاهات. فلا عجب أن النفس البشرية مجبولة على الاستعداد للتكوين الخلقي والتهذيب السلوكي. هـ التربية الوجدانية، يتكوّن النمو الوجداني أو الانفعالي من العواطف

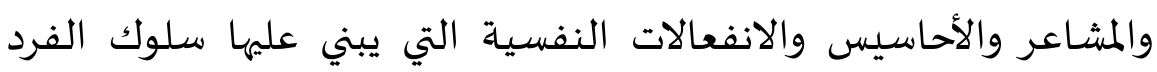
وتطبع مزاجـه الشخصي بطابع خاص وتؤثر في مواقفه واتجاهاته في الحياة وتتأثر بها صحّتـا النفسية والعقلية والجسدية أبلغ تأثير في مختلف مراحل مواحل نموّه وعمره.

\section{r. المكونات في التربية الأسرية}

كانت للتربية الأسرية مكوناتها الخاصة وهي نظام لله دور في تقدّم العملية لتحقيق

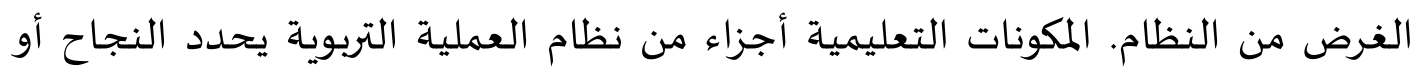


Ta'Cim al-'Arabiyyah : Jumal Pendidikan Bahasa Arab dan Kebahasaaraban, 3 (2), 2019

الفشل. ويمكن القول إن سير التربية الأسرية في حاجة ماسة إلى وجود هذه المكونات (أبو

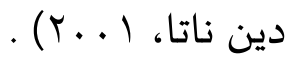

$$
\begin{aligned}
& \text { من المكونات في التربية الأسرية: }
\end{aligned}
$$

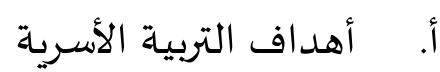

$$
\begin{aligned}
& \text { وهذه الأهداف تنقسم إلى ثلاثة النواحي: }
\end{aligned}
$$

1) الناحية الشخصية، وهي إعداد الأبناء لتحمّل العبء في مواجهة الحياة

$$
\text { المستقبلية. }
$$

r) الناحية الخلقياة، هي توجيه الآباء وإرشادهم نحو الأخلاق السـامياة

$$
\text { والكريماة وحثهم على الابتعاد عن الأخلاق الرذيلة. }
$$

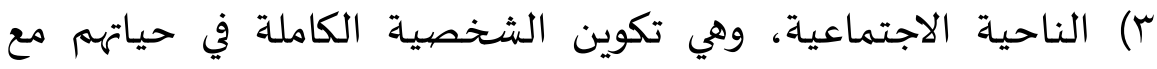
المجتمع وتحويل الإنسان إلى فرد اجتماعي قادر على التفاعل مع أفراد

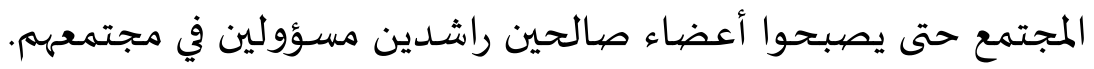

$$
\text { ب. ب ب الآباء }
$$

إن وجود الآباء في حياة الأبناء يعنى الحماية والرعاية وهي القدوة والسلطة والتكامل الأسري. من المعروف أن مسؤولية تربية الأبناء تقع على الأب والأم

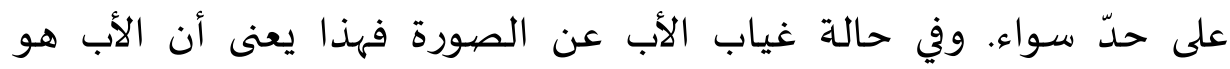
المسؤول عن توطيف دوره في الأسـرة. ج. الأبناء

والأبناء أمانات جعلهم الله عند الآباء وأوصوهم بتربيتهم تربية صالحة لأبدانهم وقلوبهم وعقولهم ودينهم ودنياهم وآخرتهم. ومن هنا ورد الترغيب في

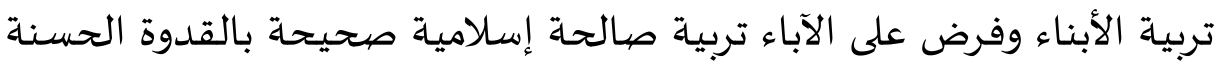

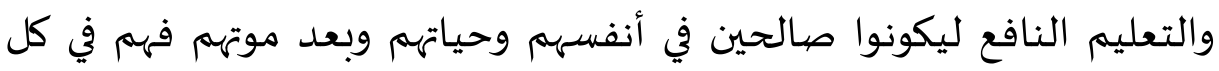
وقت يدعون لآبائهم بالمغفرة والرحمة.

التضمين التربوي الأسري من معاني ألفاظ سكينة ومودة ورحمة في القرآن الكريم 
Ta'lim al-'Arabiyyah : Jurnal Pendidikan Bahasa Arab dan Kebahasaaraban, 3 (2), 2019

التضمين التربوي الأسري من معاني ألفاظ سكينة ومودة ورحمة في القرآن الكريم يتعلق بتربية الأبناء التي تتأسس على الرحمة والمحباة. فمن اللازم أن تقوم التربية الأسرية على المبادئ النفسية التي تستمد من القرآن الكريم ومنها ما يعتمد على محاور السكينة والمودة والرحماة بوصفها وحدة مترابطة متماسكة في بناء الأسرة السعيدة. تتحقق التربية الأسرية على هذه المحاور بمراعاة الخصائص المعانية المتعلقة بها على حدة كما يلي:

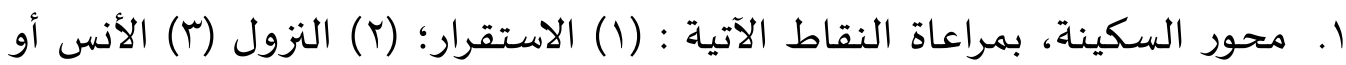
الاستئناس؛ (ع) الطمأنينة.

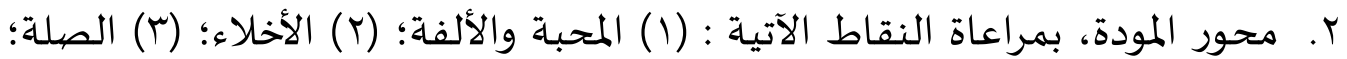

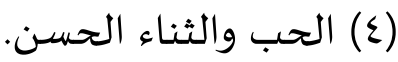
r. محور الرحمة، بمراعاة النقاط الآتية: (1) الجنة؛ (؟) الرزق؛ (r) الخير؛ (ع)

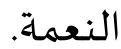
النتائج النتائج المحصولة من هذا البحث ما يلي: (1) استعمال ألفاظ سكينة ومودة ورحمة منها ما يستعمل في آيات مستقلة وهي الأكثر وما يستعمل في آية واحدة وهي في الآية (Yl) من سورة الروم. (Y) من المعاني المعجمية للفظ سكينة الطمأنينة والاستقرار والسكون الذي ينزله الله في قلب عبده عند اضطرابه من شدة المخاوف و لفظ مودة بمعنى محبة الشيء وتمني وجوده ولفظ رحمة بمعنى رقة تقتضى الإحسان إلى المرحوم. ومن المعاني السياقية للفظ سكينة الاستقرار والنزول والأنس والطمأنية؛ والمعاني السياقية للفظ مودة منها المحبة والألفة والأخلاء والصلة والحب والثناء الحسن؛ وللفظ رحمة منها الجنة والرزق والمطر والخير والنعمة والنبوة. (r) العلاقة الدلالية بين ألفاظ سكينة ومودة ورحمة في نطاق تنافر انتسابي لأن هذه الألفاظ الثلاثة تدل على انضيواء مجموعة من الكلمات تحت المعنى العام وهو السعادة حيث إن من مقومات السعادة في الحياة الزوجية بناء الأسرة التي تسودها السكينة والمودة والرحمة. (ع) أن لمعاني ألفاظ سكينة ومودة ورحمة في القرآن الكريم تضمينا تربويا أسريا يتعلق بتربية الأبناء التي تتأسس على الرحمة 
Ta'Cim al-'Arabiyyah : Jumal Pendidikan Bahasa Arab dan Kebahasaaraban, 3 (2), 2019

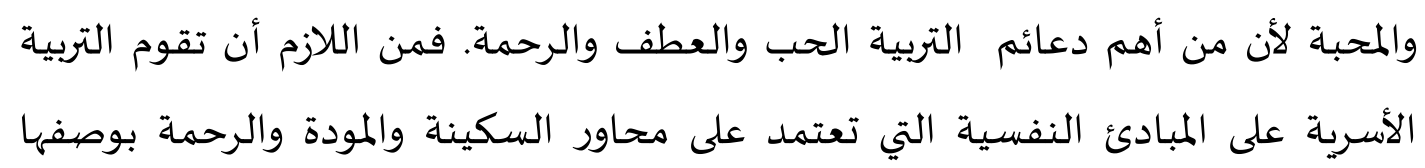
وحدة مترابطة في بناء الأسرة السكينة.

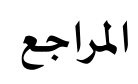

Al Fauzan, Abdurrahman bin Ibrahim. 2002. Idhäat li Mu'allimì al Lughah al 'Arabiyyah Li Ghairi al Nathiqina Bihā. Beirut: D Acep r Ilmiyah.

Al Khuli, Muhammad Ali. 1982. Asälïb Tadrid al Lughah al'Arabiyyah. Riyadh: al Malakat al 'Arabiyyah.

Al Nāqah, Muhammad Kāmil. 1985. Ta'lìm al Lughah al 'Arabiyyah li Näthiqina Bilughäti Ukhra. Saudi: Jami’ah Ummul Qura

Al Shabūnī, Muhammad Ali. Shafwatu al Tafäsir. Beirut: Dār al Qurān al Karīm.

Arikunto, Suharsimi. 2010. Prosedur Penelitian Suatu Pendekatan Praktik. Jakarta: pt. Rineka Cipta.

Hermawan, Acep. 2011. Metodologi Pembelajaran Bahasa Arab. Bandung: P'T Remaja Rosdakarya.

Ibrahim, Abdul Alim. 1962. Al Muwajiih al Fanni limudarris al Lughah al 'Arabiyyah. Kairo: Daar al Ma'arif.

Lubis, Amani. 2018. Al amn al Usrī min Mandzūr al Isläm. Jakarta: Pustaka Cendekiawan.

Mandzur, Ibnu .1991. Lisān al 'Arab. Beirut: Daar al Shādir.

Mujahid, Abdul Karim. 1985. Al Dilälah al Lughawiyyah Inda al 'Arab. Urdun: Dār al Qadlā.

Shalih, Sa’ād Ibrahim. 2000. Adlwāu 'Alā Nidæām al Usrah fì al Islam. Jeddah: Tahamah. 
Ta'lim al-'Arabiyyah : Jurnal Pendidikan Bahasa Arab dan Kebahasaaraban, 3 (2), 2019

Tinungki, G. M. (2015). The Role of Cooperative Learning Type Team Assisted Individualization to Communication Ability in the Subject of Probability Theory. Journal Of Education and Practice, 6 (32).

Umar, Ahmad Mukhtar. 1992. Ilm al Dilālah. Kairo: Dār al Ihyā al Turāts al 'Arabi.

Arikunto, Suharsimi. 2002. Prosedur Penelitian Suatu Pendekatan Praktek. Jakarta: Rineka Cipta.

Chaer, Abdul. 2002. Pengantar Semantik Bahasa Indonesia. Jakarta: Rineka Cipta.

Djajasudarma, T. Fatimah. 1993. Metode Linguistik: Ancangan metode penelitian dan kajian. Bandung: Eresco.

-. 1999. Semantik I Pengantar ke Arah Ilmu Makna. Bandung: Refika.

Gunawan, Heri. 2016. Dasar-dasar Metodologi Penelitian Pendidikan. Bandung.

Narimawati, Umi. 2009. Metodologi Penelitian Kualitatif dan Kuantitatif, Teori dan Aplikasi. Bandung: Agung Media.

Natta, Abuddin. 1998. Al Quran dan Hadits. Jakarta: PT Raja Grafindo.

Nazir, Muhammad. 1998. Metode Penelitian. Jakarta: Ghalia Indonesia.

Pateda, Mansoer. 2001. Semantik Leksikal. Jakarta: Rineka Cipta.

Tajudin, Nur. 2017. Semantik Bahasa Arab Pengantar Studi Ilmu Makna. Bandung: SEMIOTIKA

‘Āsyur, Muhammad Thāhir Ibn. 1984. Tafsìr al Tharìr wa al Tanwīr. Tunis. Jam’ì Huqūq al al Thab’ Mahfūdzah li Dār al Tūnisiyyah li Nasyr.

Katsir, Ismail. 1999. Tafsìr al Qurān al 'Adð̨ìm. Dār Thoyibah li Nasyr wa al Tauzi'. 